39 Lien L. Are readmission rates influenced by how psychiatric services are organized? Nord J Psychiatry 2002; 56: 23-8.

40 Nelson EA, Maruish ME, Axler JL. Effects of discharge planning and compliance with outpatient appointments on readmission rates. Psychiatr Serv 2000; 51: 885-9.

41 Oiesvold T, Saarento O, Sytema S, Vinding $\mathrm{H}$, Gostas $\mathrm{G}$, Lonnerberg $\mathrm{O}$, et al. Predictors for readmission risk of new patients: the Nordic Comparative Study on Sectorized Psychiatry. Acta Psychiatr Scand 2000; 101: 367-73.
42 Sullivan G, Wells KB, Morgenstern H, Leake B. Identifying modifiable risk factors for rehospitalization: a case-control study of seriously mentally ill persons in Mississippi. Am J Psychiatry 1995; 152: 1749-56.

43 Walker R, Minor-Schork D, Bloch R, Esinhart J. High risk factors for rehospitalization within six months. Psychiatr Q 1996; 67: 235-43.

44 Nasir $\mathrm{K}$, Lin Z, Bueno $\mathrm{H}$, Normand SL, Drye EE, Keenan PS, et al. Is samehospital readmission rate a good surrogate for all-hospital readmission rate? Med Care 2010; 48: 477-81.

45 Tomita A, Herman DB. The impact of critical time intervention in reducing psychiatric rehospitalization after hospital discharge. Psychiatr Serv 2012; 63: $935-7$.

\title{
Back Ward at Glenside
}

\section{poems by doctors}

\author{
The years are a tide on this shore \\ That has ebbed into distance \\ Leaving row after row of bedstead \\ Washed-up like driftwood \\ Where I am called in the dead of night. \\ I lock the door behind me \\ And sink into a fabulous noise \\ That rises like the keening of gulls \\ Scattered on a seaweed wind. \\ Here all our grandparents stand dribbling \\ And half naked on the smooth vinyl, \\ Staring with the tired eyes of fish. \\ Forgetting what was forgotten \\ They part as I am led to a bed in the corner. \\ For some reason the smell of pine forests \\ Thick with evening drifts from the blankets \\ Clutched by fingers bleached bone white, \\ But she is pale and pulseless now \\ With the smashed crab of nothing-to-be-done \\ From where she fell \\ Matted in her hair. \\ I fill out a form that she does not need \\ And notice in her notes a photograph \\ Faded and brown, a young woman \\ With smooth skin and a squint \\ Smiling at something \\ Beyond the camera. \\ Pigtails and lace collar dated 1920, insane. \\ Back behind the curtains \\ I lift the sheet clear of her face \\ And meet the same smile and cloudy eyes \\ Staring over my shoulder \\ To what was always out of sight, \\ Just behind this moment, \\ Her seventy lost years eddying into night.
}

Charles Montgomery, Consultant Psychiatrist, Exeter. 